\title{
Updated System for the Sea Wave Operational Forecast of the Black Sea Marine Forecasting Center
}

\author{
Yu. B. Ratner ${ }^{凶}$, V. V. Fomin, A. L. Kholod, A. M. Ivanchik \\ Marine Hydrophysical Institute of RAS, Sevastopol, Russian Federation \\ 凶yubrat@gmail.com
}

\begin{abstract}
Purpose. The work is aimed at updating the sea wave forecasting system developed in the Black Sea Marine Forecasting Center by including the block of wind wave forecast in the Sevastopol region and by improving the wave forecast accuracy using the proposed procedure for the SWAN model tuning. Methods and Results. In the updated forecasting system, the possibility of performing the joint operational sea wave forecasts for the Black Sea and the Sevastopol region (with the 5 and $1 \mathrm{~km}$ spatial resolutions, respectively) became possible due to the nested grid method applied. To improve accuracy of the wave forecasts, the procedure for the $S W A N$ model tuning was proposed. It is based on changing the parameterization of the surface friction coefficient $C_{d}(V)$, where $V$ is the surface wind speed. This permits to reduce the deviations of the forecasted wave heights from those obtained from the satellite altimetry measurements. Efficiency of the proposed procedure was assessed through comparison of the forecasting results with the remote sensing data. It is shown that in the forecasts supplied with an optimal choice of functional dependence $C_{d}(V)$, the scattering index between the forecasted and measured values can be reduced by $20 \%$.

Conclusions. Represented is the updated system of the Black Sea Marine Forecasting Center intended for the joint operational sea wave forecasts in the Black Sea and in the Sevastopol region. The results of model validation have shown that the procedure proposed for tuning the SWAN model makes it possible to reduce the deviations of the forecasted wave heights from those measured by the sensors installed at the altimetry satellites.
\end{abstract}

Keywords: Black Sea, SWAN, automatic system, wave forecast, model tuning, model parameters, surface friction coefficient, satellite measurements, altimetry measurements, wave height, validation, visualization, server

Acknowledgments: the work was carried out at financial support of the RFBR grant No. 18-45-920059 p_a and within the framework of the state task of Marine Hydrophysical Institute, RAS on theme No. 0555-2021-0003 "Development of methods of operational oceanology based on interdisciplinary studies of the processes of the marine environment formation and evolution, and mathematical modeling using the data of remote and contact measurements".

For citation: Ratner, Yu.B., Fomin, V.V., Kholod, A.L. and Ivanchik, A.M., 2021. Updated System for the Sea Wave Operational Forecast of the Black Sea Marine Forecasting Center. Physical Oceanography, [e-journal] 28(5), pp. 579-595. doi:10.22449/1573-160X-2021-5-579-595

DOI: 10.22449/1573-160X-2021-5-579-595

(C) Yu. B. Ratner, V. V. Fomin, A. L. Kholod, A. M. Ivanchik, 2021

(C) Physical Oceanography, 2021

\section{Introduction}

System for wind wave diagnosis and forecast for the Black Sea and the Sevastopol region is important for solving both scientific problems related to the wave regime study and applied ones related to assessing its impact on various aspects of economic activity and the environment. At the same time, the $3^{\text {rd }}$ generation WAM [1], WAVEWATCH [2] and SWAN [3] spectral wave models are most widely used in fundamental and applied studies of wind waves.

Over the past several years, a large number of works on various aspects of mathematical modeling of wind waves in the Black Sea based on various wave 
models have been published. The work [4] analyzed the stormy climate in the western Black Sea using a continuous set of retrospective data for 63 years. Numerical modeling of wind waves for some coastal regions of Crimea was carried out in [5]. Results of the variability analysis of interannual and seasonal wind wave variations are published in [6]. In [7], the model sensitivity estimates to changes in input parameters are given. In [8, 9], the results of numerical modeling of storm waves in the Black Sea using various types of atmospheric reanalysis were presented. In [10], the wind-wave climate variability over the past 37 years was studied.

In [11], a system of operational wind wave forecast in the Black Sea with a spatial resolution of $5 \mathrm{~km}$, developed based on SWAN model, was announced. Comparison of the results of wind wave modeling obtained by us with the results of other authors showed their satisfactory agreement. This paper presents the results of this system modernization aimed at improving the sea wave forecast reliability, by connecting the embedded wave forecast subsystem for the Sevastopol region with a spatial resolution of $1 \mathrm{~km}$, as well as the results of tuning the model parameters for the Black Sea in general and the Sevastopol region in particular.

\section{Modernization of the sea wave forecasting system of the Black Sea Marine Forecasting Center for carrying out calculations of wave characteristics in the Sevastopol region}

For predictive calculations of waves in the Sevastopol region with a higher spatial resolution, compared to the rest part of the Black Sea, the SWAN model provides two options for modernization. The first option is to switch from regular spatial grids, the calculations are carried out in the existing Black Sea Marine Forecasting Center wave forecasting system on, to the use of unstructured computational grids with condensed nodes in the Sevastopol region. This option requires significant improvements of the existing system. Therefore, the second option was used, based on the use of a two-step nested grid method. At the first step, a wave forecast was carried out on a grid covering the entire Black Sea area. At the second step, waves in the Sevastopol region were simulated on a finer grid. The wave parameters at the liquid boundaries of the second grid were determined by interpolating the model data obtained at the first step. The characteristics of the grids used are given in Table 1.

Table 1

Characteristics of spatial grids of the models

\begin{tabular}{c|c|c|c}
\hline Number of nodes & ${ }^{\circ} \mathrm{E}$ & Number of nodes & ${ }^{\circ} \mathrm{N}$ \\
\hline \multicolumn{4}{c}{ Black Sea } \\
\hline 238 & $27.4122-41.895535$ & 132 \\
\hline \multicolumn{4}{c}{ Sevastopol region } \\
\hline 268 & $32.003128-34.229286$ & 152 \\
\hline
\end{tabular}

Wave characteristics were calculated using the SWAN model (version 41.20) using OpenMP technology for multi-core processors. The bottom relief for the Black 
Sea water area was set in the same way as in the Black Sea Marine Forecasting Center systems [11, 12]. For the Sevastopol region, the bottom topography was prepared based on the use of database ${ }^{1}$ with a spatial resolution of $30 \mathrm{~s}$. An irregular grid with 31 nodes was used along the frequency coordinate varying in the range of 0.05-1.0 Hz. Angular resolution of the model was $10^{\circ}$. Time integration step was 30 min. Bottom friction was determined based on the Grant - Madsen theory [13]. Other SWAN model parameters were selected by default. An implicit time integration scheme was used.

As the main source of wind data, the results of atmospheric forecasts of SKIRON center (Greece) [14] at a standard height of $10 \mathrm{~m}$ with a time discreteness of $3 \mathrm{~h}$ and a spatial resolution of $10 \mathrm{~km}$ were used. In rare cases, when these data were absent, as an additional source, a sample of forecast data from the PLAV 20 global model of the FSBI "Hydrometeorological Center of Russia" for the Black Sea at a standard height of $10 \mathrm{~m}$ with a time resolution of 3 hours and a spatial resolution of $22 \mathrm{~km}$ was used. This data obtaining via Internet was carried out daily in automatic mode by the Black Sea Marine Forecasting Center input system [12].

The wave forecast system in the Black Sea and in the Sevastopol region is currently working in a test mode and performs the standard sequence of actions provided for operational forecasts - from planning calculations to recording the results of wave height, direction and period calculations in the local archives of the Black Sea Marine Forecasting Center. Functional scheme of the system is shown in Fig. 1. It is similar to the functional scheme given in [11], with the exception of the block that predicts waves in the Sevastopol region, which is included in the system during its modernization. Forecasts are made daily according to a cyclically repeated scheme. One cycle contains the results of wave forecasts for 5 days. The system operation is controlled using script files developed in the CalcmanPack language and executed by the CalcMan software package interpreter programs [15].

During the system operation, work logs are created for each calculation cycle separately. They record the results of each step of the work and the problems appearing during the forecast course.

The main output data of the system are the fields of significant waves heights (the mean value of heights is $1 / 3$ of the highest waves in the wave spectrum), the mean direction of wave propagation, mean periods and mean wavelengths. Additionally, the characteristics of the frequency-angular spectrum of waves are displayed at five points of the Sevastopol region.

Coordinates of the points the data on the frequency-angular spectrum of waves is displayed at are as follows:

$\begin{array}{cccccc}\text { Node No. } & 1 & 2 & 3 & 4 & 5 \\ { }^{\circ} \mathrm{E} & 33.318909 & 32.919743 & 32.922863 & 33.342297 & 33.785118 \\ { }^{\circ} \mathrm{N} & 44.574348 & 44.574348 & 44.242233 & 44.270298 & 44.278095\end{array}$

\footnotetext{
${ }^{1}$ GEBCO - The General Bathymetric Chart of the Ocean. 2021. [online] Available at: https://www.gebco.net [Accessed: 20 September 2021].
} 


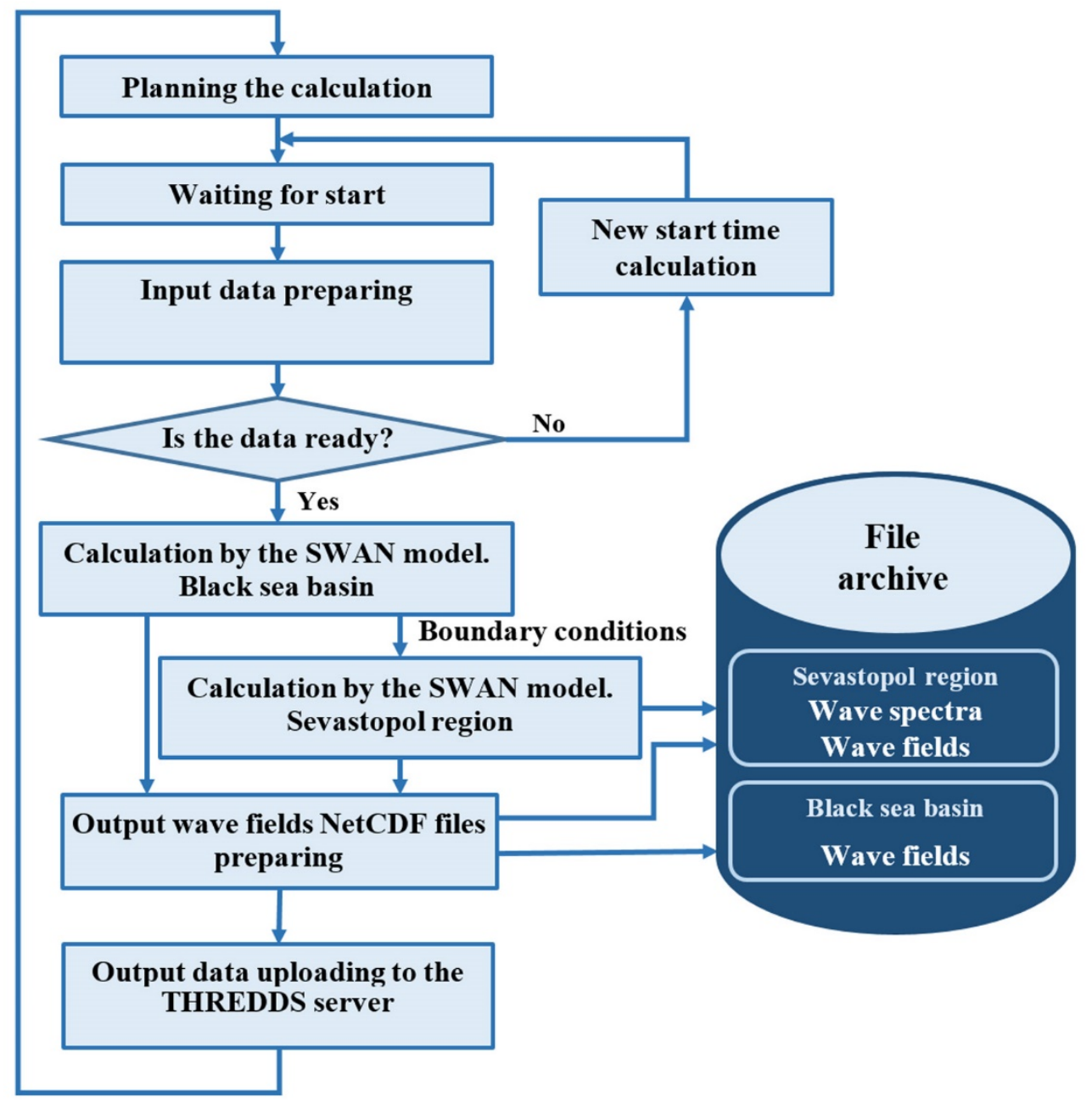

F i g. 1. Functional scheme of the system of joint sea waves forecasts in the Black Sea and in the Sevastopol region

All results of test calculations for July 2017 - June 2019 are stored in the local archive of the Black Sea Marine Forecasting Center.

The results of calculations of the fields of sea waves parameters are recorded in NetCDF format files. The results are issued every hour, each file contains data for one day of the forecast. To visualize the wave forecast results, software written in the $\mathrm{R}^{2}$ programming language was developed. One of the examples of visualization of the sea wave forecast results for the Sevastopol region is shown in Fig. 2.

${ }^{2}$ The R Core Team, 2016. R: A language and Environment for Statistical Computing. Vienna, Austria: R Foundation for Statistical Computing. Available at: https://www.R-project.org/ [Accessed: 20 September 2021]. 


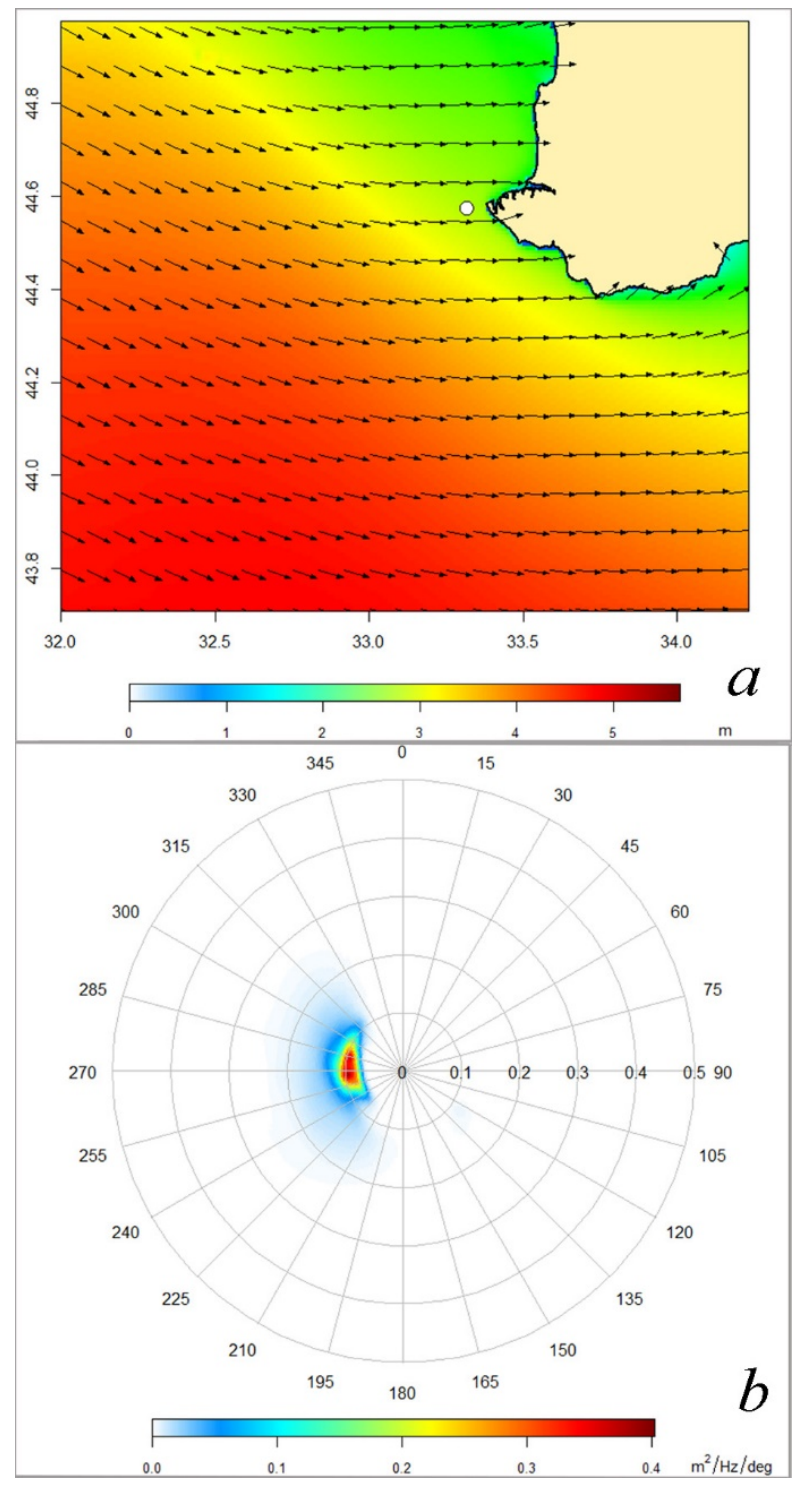

F i g. 2. Example of visualizing the results of the sea waves forecast for the Sevastopol region for 19.01.2018: $a$ - the height of significant waves (color) and the average direction of wave propagation (arrows); $b$ - the frequency-angular spectrum at the point marked with a white circle in Fig. 2, $a$

\section{Satellite measurement data used to set up the model and validate sea wave forecast results}

One of the important tasks associated with the wave forecasting system modernization concerns the comparison of forecast results with observational data. Various types of measuring equipment are currently used to monitor sea waves. In areas relatively close to the coast, the in situ data obtained from wave buoys [16, 17], laser level gauges and ultrasonic wave recorders are used. The data of coastal radar stations designed to measure the sea waves characteristics and string wave recorders can also be used. However, we do not have any of these data sources. Therefore, the 
data on the significant waves heights obtained using methods based on satellite altimetry measurements were compared with the results of the forecasts.

Archives of data from satellite altimetry measurements of the significant waves height for 2017-2019 were prepared. The created data archives contain the Global ocean L3 significant wave height from NRT satellite measurement ${ }^{3}$ product of the Copernicus Marine Environment Monitoring Service ${ }^{4}$. In total, from July 2017 to June 2019, about 6,000 altimetric measurements of wave heights from CryoSat-2, Jason-3, Sentinel-3A and AltiKa satellites were carried out over the Sevastopol region water area. During the same period about 139.000 altimetry measurements were carried out over the Black Sea basin.

\section{Features of the proposed procedure for the SWAN model tuning}

Results of the basic version validation of the system for the Black Sea water area, given in [11], and similarly performed validation of the modified system for the Black Sea and Sevastopol region water areas according to altimetry measurements for 2017-2019, showed a noticeable underestimation of the calculated values of the significant waves height in relation to the data of satellite measurements in conditions of moderate and strong waves. This effect is noted not only in our results, but also in other works. For example, in [16, 17] it is assumed that it is associated with insufficient accuracy of the model parameters tuning in the sources describing the wave energy generation and dissipation in the Black Sea. This problem is solved by additional tuning of the model parameters using in situ data and satellite altimetry measurements of the significant waves heights.

In most wave models and in the SWAN model particularly, the main parameter responsible for the generation and dissipation of waves is the wind friction velocity $u_{*}$, calculated based on the data of atmospheric models on the near-surface wind velocity $V$. The calculation of the $u_{*}$ value is carried out using the formula $u_{*}^{2}(V)=$ $=C_{d}\left(V, \alpha_{1}, \ldots, \alpha_{n}\right) V^{2}$, where $C_{d}$ is the air friction coefficient; $\alpha_{i}$ are the numeric parameters. In SWAN model, the dependence $C_{d}\left(V, \alpha_{1}, \ldots, \alpha_{n}\right)$ is given by a quadratic function with fixed coefficients, the change of which, in contrast to the parameters in the sources describing the wave energy generation and dissipation, is not provided. But in fact, the $C_{d}$ coefficient is known with almost the same degree of uncertainty [18-22] as the parameters of mathematical models describing the dissipation and generation of sea waves. Uncertainty in the $C_{d}$ value is especially typical for coastal regions located at a distance of up to 100-200 km from the coast. Near the coast, the effects of stratification of the near-surface layer of air and specific features of the interaction of the atmosphere near-surface layer and the underlying surface are manifested. They are inherent in each individual local coastal region where predictive calculations of waves are carried out. Their description is given,

${ }^{3}$ CMEMS team. Global ocean L3 Significant Wave Height from NRT Satellite Measurements. E.U. Copernicus Marine Service Information. 2021. [online] Available at: ftp://nrt.cmemsdu.eu/Core/WAVE_GLO_WAV_L3_SWH_NRT_OBSERVATIONS_014_001/dataset-wav-alti-l3-swh-rtglobal-al/ [Accessed: 20 September 2021].

${ }^{4}$ CMEMS team. The Copernicus Marine Service. [online] Available at: http://marine.copernicus.eu/documents/QUID/CMEMS-WAV-QUID-014-001.pdf [Accessed: 20 September 2021]. 
for example, in [23-25]. They should in one way or another affect the character of the $C_{d}(V)$ dependence, and must be taken into account when calculating sea waves.

In view of the above, it is of interest to test the procedure for $S W A N$ wave model tuning based on varying the shape and parameters of the $C_{d}\left(V, \alpha_{1}, \ldots, \alpha_{n}\right)$ dependence. Tuning and control of accuracy within the framework of the proposed method are based on the only available source of information about waves in the Sevastopol region and the Black Sea - data from satellite altimetry measurements of the significant waves height. According to [24], their reliability roughly corresponds to the accuracy of contact measurements of the height of significant waves from offshore platforms ${ }^{5}$. Since the spatial resolution of wave data obtained from satellite altimeters is $7 \mathrm{~km}$, strictly speaking, this model can be applied in conditions of homogeneity fields of sea waves heights at scales of $7-10 \mathrm{~km}$.

The proposed tuning procedure has a number of common features with the procedures for controlling the accuracy of the wave heights forecast $[9,11,16,17]$. During this procedure, a joint data sample, containing the results of calculations of the heights of significant waves and the corresponding satellite measurements, is also formed. These combined measurements are used to assess statistical criteria for deviations between the calculated and measured heights of significant waves, used to control the change in the accuracy of calculations during the model tuning process. When forming a joint sample in [11], the data of model calculations was linearly interpolated in space and time to points and moments of remote measurements. A similar procedure is used in the present paper.

An additional problem arises when performing model tuning. It is connected with the fact that, due to the natural variability of the wind and the heights of significant waves, the resulting joint sample contains too much data corresponding to weak waves with heights of significant waves less than 1-1.5 m. As a result, the representativeness in relation to moderate and severe wave conditions is disturbed. Therefore, if the tuning is carried out on such complete samples of joint measurements, it turns out that the model will work well in conditions of weak waves, and unsatisfactory in conditions of strong waves. One of the possible solutions is to keep joint measurements from the available data only for those days when, according to satellite data and model calculations using the current operational model [11], a sufficiently high repetition rate of moderate and strong sea conditions is observed. As a result, the joint sample size is reduced by an order of magnitude, but the efficiency of model tuning for situations of strong waves is significantly improved without deteriorating the results for situations with low heights of significant waves. Additionally, the time spent on calculations is reduced by about an order of magnitude. The aforementioned will be confirmed by the results of the present study, given below.

The proposed tuning procedure is limited to varying the parameters of the dependence $C_{d}\left(V, \alpha_{1}, \ldots, \alpha_{n}\right)$ to ensure the minimum value of the scattering index [11] between the calculated and measured heights of significant waves. Optimization according to this criterion is carried out under additional conditions of smallness of the systematic error and the correlation coefficient $\operatorname{Cor}_{E}$. These

${ }^{5}$ The European Space Agency. Sentinel-3 Altimetry Technical Guide. [online] Available at: https://sentinel.esa.int/web/sentinel/technical-guides/sentinel-3-altimetry [Accessed: 20 September 2021].

PHYSICAL OCEANOGRAPHY VOL. 28 ISS. 5 (2021) 
parametera are estimated by the deviations of the simulated significant waves heights from the values obtained from the data of satellite measurements, as well as with restrictions imposed on the functional dependence $C_{d}\left(V, \alpha_{1}, \ldots, \alpha_{n}\right)$ by the known theoretical concepts and experimental data about it [22, 23]. This guarantees the optimal tuning of the model according to the criterion of the minimum scattering index and, at the same time, the absence of a large systematic shift and a linear trend of deviations of the calculated wave heights relative to the measured values, while maintaining the physical admissibility of the used parameterization. Due to this, the linear regression of the calculated wave heights to their measured values approaches the function, with the scheme corresponding to equal values of the calculated and measured wave heights, and the correlation coefficient between the calculated and measured heights of significant waves turns out to be as close as possible to 1. At the same time, the other parameters of SWAN model remain unchanged - with the values set in the basic version of our prognostic system [11].

The correlation coefficient between the deviations of the heights of significant waves from the values obtained from the data of satellite measurements $\operatorname{Cor}_{E}$ is calculated by the following formula

$$
\operatorname{Cor}_{E}=\frac{\sum_{i=1}^{N}\left(S W H_{M i}-\overline{S W H}_{M}-S W H_{S i}+\overline{S W H}_{S}\right)\left(S W H_{S i}-\overline{S W H}_{S}\right)}{\sqrt{\sum_{i=1}^{N}\left(S W H_{M i}-\overline{S W H}_{M}-S W H_{S i}+\overline{S W H}_{S}\right)^{2} \sum_{i=1}^{N}\left(S W H_{S i}-\overline{S W H}_{S}\right)^{2}}} .
$$

Here $S W H_{M i}$ and $S W H_{S i}$ - the $i$-pair of calculated and measured wave heights corresponding to each other; $\overline{S W H}_{M}$ and $\overline{S W H}_{S}$ are the calculated and measured heights of significant waves, respectively, averaged over the sample. The rest of the mentioned statistical characteristics are calculated by the formulas given in $[11,17]$.

In the present paper three variants of $C_{d}\left(V, \alpha_{1}, \ldots, \alpha_{n}\right)$ dependence parametrization are considered. Variant V1 corresponds to $C_{d 1}(V)=\alpha_{1}+\alpha_{2} V+\alpha_{3} V^{2}$ with the values of $\alpha_{i}$, set as in SWAN model. In variant V2 the dependence $C_{d 2}\left(V, \alpha_{1}, \ldots, \alpha_{n}\right)=\alpha_{1}+\alpha_{2} V+\alpha_{3} V^{2}$ was chosen qualitatively corresponding to the dependence used in SWAN model (concave parabola), but the coefficients $\alpha_{1}, \alpha_{2}, \alpha_{3}$ were selected based on the optimization procedure described above. For variant V3 the dependence $C_{d 3}\left(V, \alpha_{1}, \ldots, \alpha_{n}\right)=\alpha_{1} / V+\alpha_{2}+\alpha_{3} V$ was chosen in accordance with [23], and the optimal coefficients were selected in the same way as in variant V2. Variant V3 was also considered, since parametrizations of this type are found in a number of works devoted to the study of the dependence of the friction coefficient on the wind speed. Some of these works are cited in [18] and are shown in the present study in Fig. 3.

At the start of the tuning, it is necessary to set the type of functional dependence of the surface friction coefficient $C_{d t}\left(V, \alpha_{1}, \ldots, \alpha_{n}\right)$, where $t=2$ or $t=3$, as well as the initial values of the $\alpha_{i}$ parameters and carry out predictive calculations for the Black Sea and the Sevastopol region waters with subsequent evaluation of the optimization criteria. Then, in order to find the optimal values of the $\alpha_{i}$ coefficients, 586

PHYSICAL OCEANOGRAPHY VOL. 28 ISS. 5 (2021) 
it is necessary to carry out their directional change using any procedure for optimizing the $\alpha_{i}$ values according to the selected criterion, taking into account the accepted restrictions mentioned above, with the calculation and assessment of the statistical characteristics of deviations for the newly selected parameter values. As a result of the cyclical repetition of these actions, a set of statistics of deviations of the predictive values of significant wave heights from their measured values is formed with a sequentially decreasing scattering coefficient. When an acceptable result is achieved, the procedure should be stopped.
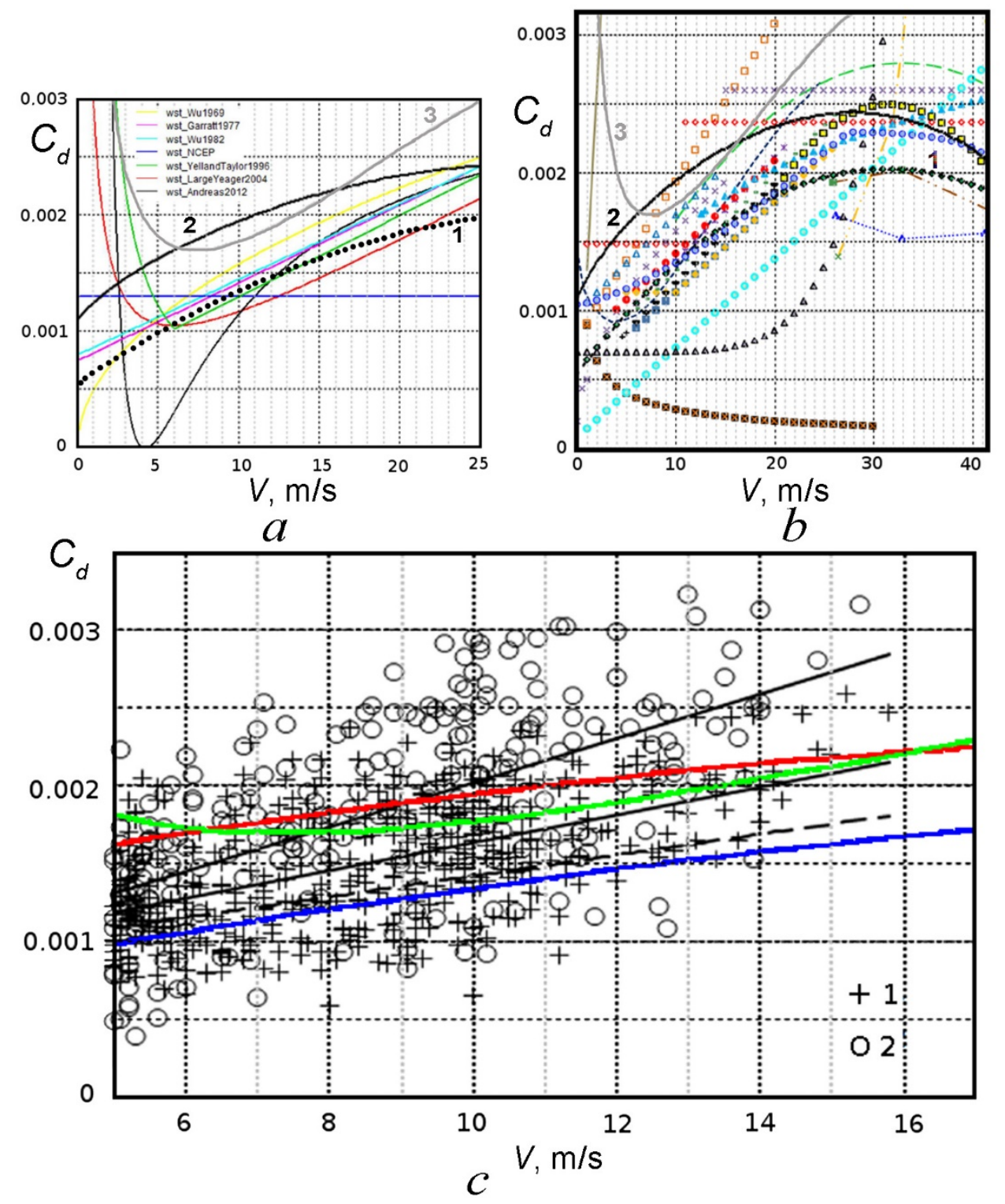

F i g. 3. Dependence of the coefficient $C_{d}(V)$ according to the data from [18, p. 293] (a), [19, p. 3] (b), [25, p. 58] (c) 


\section{Results of the model tuning}

The proposed tuning procedure was applied only for the Sevastopol region. During its practical implementation, in order to get around the need to make changes to the text of the SWAN model program, the original dependency was replaced as follows. Instead of the initial values of the wind speed vector, the transformed values were fed to the model input: the speed vector direction was not changed, and its modulus was determined in accordance with the relation $V_{t}=V \sqrt{C_{d t}\left(V, \alpha_{1}, \ldots, \alpha_{n}\right) / C_{d 1}(V)}$. Note that the above formula for converting wind speed can be generalized, but it is beyond the scope of this paper aims. It is easy to show that with such a change, the wind friction velocity used in modeling is determined in accordance with the formula

$u_{* t}^{2}=C_{d 1}\left(V_{t}\right) \cdot V_{t}^{2}=C_{d t}\left(V, \alpha_{1}, \ldots, \alpha_{n}\right) \cdot \frac{C_{d 1}\left(V_{t}\right)}{C_{d 1}(V)} \cdot V^{2}=\hat{C}_{d t}\left(V, \alpha_{1}, \ldots, \alpha_{n}\right) \cdot V^{2}$.

Formula (2) indicates that the transformation of the wind speed module is equivalent to the $C_{d}(V)$ transformation, and vice versa. Thus, the errors in wind speed forecasting can be to some extent compensated by the transformation of the surface friction coefficient in accordance with (2). It also follows from (2) that the results of model tuning by $C_{d}(V)$ correction depend on the used source of wind speed data.

In formula (2), the value $C_{d 1}\left(V_{t}\right) / C_{d 1}(V)$ at wind speeds up to $30 \mathrm{~m} / \mathrm{s}$ and physically permissible restrictions on the $\alpha_{i}$ coefficients taken into account in the tuning process changes little and the function $\hat{C}_{d t}\left(V, \alpha_{1}, \ldots, \alpha_{n}\right)$ and $C_{d t}\left(V, \alpha_{1}, \ldots, \alpha_{n}\right)$ differ slightly from each other. Consequently, replacing the original dependence $C_{d t}\left(V, \alpha_{1}, \ldots, \alpha_{n}\right)$ with the transformed $\hat{C}_{d t}\left(V, \alpha_{1}, \ldots, \alpha_{n}\right)$ will not lead to a noticeable deterioration of the optimized criterion. This is confirmed below by the results shown in Fig. 3, 4, and in Table 2.

In Fig. 3 shows the dependences $\hat{C}_{d t}\left(V, \alpha_{1}, \ldots, \alpha_{n}\right)$ obtained in this study in comparison with data from other sources. Fig. 3, $a$ in [18, p. 293], Fig. 3, $b-$ in [19, p. 3], Fig. 3, $c-$ in [25, p. 58]. In Fig. 3, $a$ and 3, $b$, curves $1-3$ additionally show the $C_{d}(V)$ dependences, obtained for variants V1-V3, respectively. In Fig. 3, $c C_{d}(V)$ dependences for variants V2 and V3 are shown with red and green curves, respectively. The blue curve shows the dependence $C_{d}(V)$ used in SWAN model.

Analyzing the information presented in Fig. 3, $a, 3, b$, it can be concluded that the obtained parameterizations of the $C_{d}(V)$ dependence for variants V2 and V3 correspond to modern ideas about the nature of this dependence. In general, in the range of wind speeds from 0 to $30 \mathrm{~m} / \mathrm{s}$, the values of the friction coefficients $\hat{C}_{d t}\left(V, \alpha_{1}, \ldots, \alpha_{n}\right)$ exceed the corresponding $C_{d 1}(V)$ values. For variant V2, the maximum value of $\hat{C}_{d 2}\left(V, \alpha_{1}, \ldots, \alpha_{n}\right)$ is achieved at a wind speed of $28 \mathrm{~m} / \mathrm{s}$, while for the initial parameterization $C_{d 1}(V)$ - at a wind speed of $31.5 \mathrm{~m} / \mathrm{s}$. For variant V3, the values of $\hat{C}_{d 2}\left(V, \alpha_{1}, \ldots, \alpha_{n}\right)$ exceed the values of $C_{d}(V)$ corresponding to the parameterization [23], which is shown by the red curve in Fig. 3, $a$. The minimum value of the value $\hat{C}_{d 2}\left(V, \alpha_{1}, \ldots, \alpha_{n}\right)$ is achieved at a wind speed of $7.5 \mathrm{~m} / \mathrm{s}$, and with parametrization [23] it is achieved at $V=6 \mathrm{~m} / \mathrm{s}$. The slope of the $\hat{C}_{d 2}\left(V, \alpha_{1}, \ldots, \alpha_{n}\right)$ 
curve at high wind speed values slightly exceeds the slope of the $C_{d}(V)$ curve during parametrization [23].
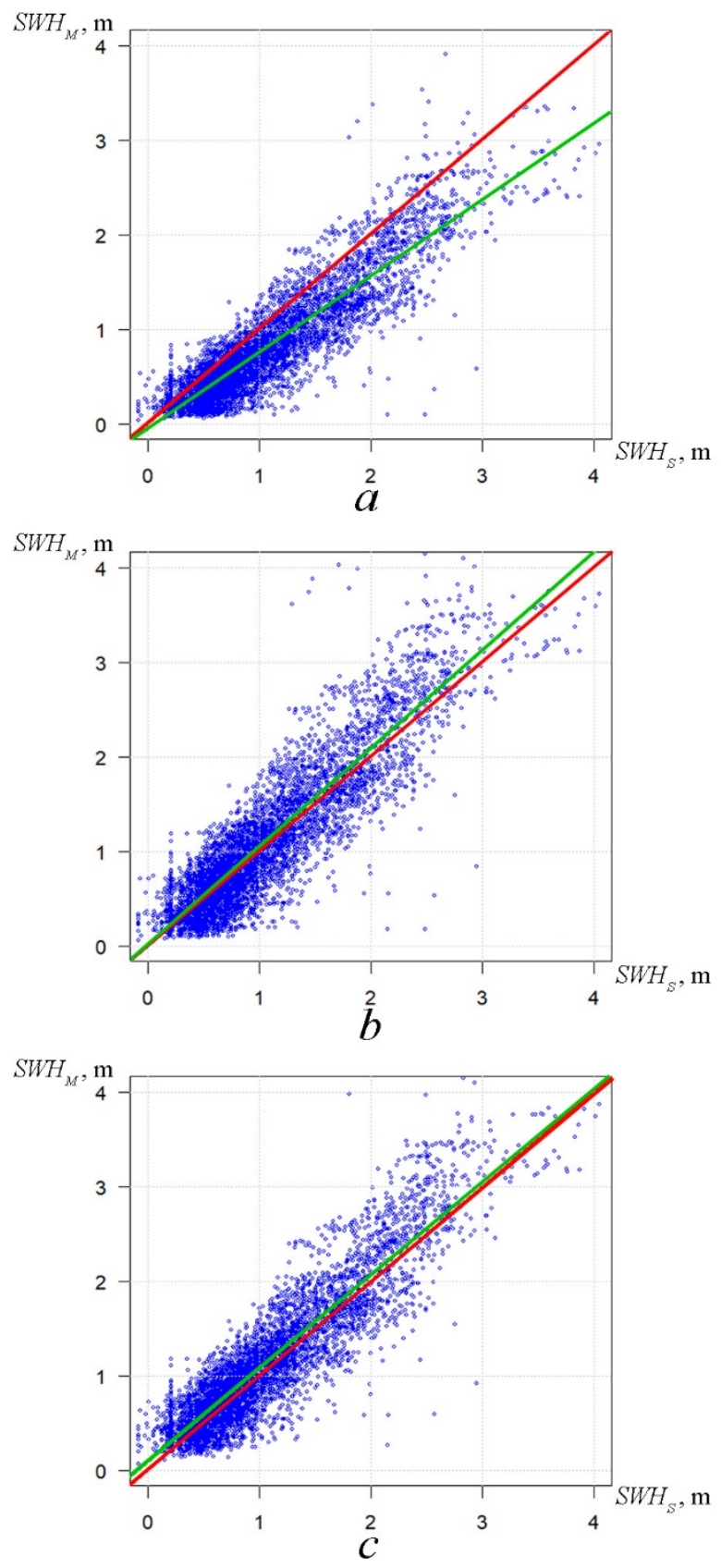

F i g. 4. Diagrams of scattering between the forecasted $\left(S W H_{M}\right)$ and measured $(S W H s)$ heights of significant waves in the Sevastopol region of the Black Sea: $a$-variant V1; $b$ - variant V2; $c-$ variant V3 
The special attention should be focused on Fig. 3, c. Here are the results of comparing the $C_{d}(V)$ dependences obtained by us with the data of the present paper [25], obtained during experimental work on the offshore platform in the region of the South coast of Crimea (Katsiveli village, the platform is located at $600 \mathrm{~m}$ from the coast), which is located in the considered Sevastopol region. The results shown in Fig. 3, $c$ show that the dependences $C_{d}(V)$ corresponding to variants V2 and V3 in the wind speed $8-16 \mathrm{~m} / \mathrm{s}$ range agree with the experimentally obtained values of the friction coefficient better than the dependence used in SWAN model.

The results of comparing the wave heights calculated with the new dependences $C_{d}(V)$, obtained as a result of the model tuning, show a significant decrease in the systematic deviations of the calculated heights of significant waves from the measured ones. This is confirmed by examples for the Sevastopol region shown in Fig. 4 and in Table 2.

Fig. 4 shows three diagrams of scattering of the calculated and satellite heights of significant waves for the Sevastopol region. The red straight lines show the lines of equal values of the calculated and measured wave heights, the green straight lines show the regression graphs of the calculated heights of significant waves by the measured values. The $C_{d 1}(V)$ dependence used in SWAN model corresponds to variant V1 shown in Fig. 4, $a$. The graph of dependence $C_{d 1}(V)$, corresponding to variant $\mathrm{V} 1$, shows the previously mentioned significant underestimation of the height of significant waves with moderate and strong winds. Fig. 4, $b$ corresponds to variant V2, Fig. 4, $c$ illustrates the results obtained on the basis of variant V3. The results shown in Fig. 4, $c$ and in Table 2 show that the scattering index between the calculated and measured wave heights for variant V3 is $11 \%$ less than for variant V2, and 20 \% less than the scattering index obtained for variant V1. In the Sevastopol region, the scattering index 0.29, corresponds to variant V3, and in some cases does it better than in the other works [16, 17, 26-32].

T a ble 2

Statistical characteristics of the differences between the forecasted and measured values of the wind wave heights in the Black Sea

\begin{tabular}{|c|c|c|c|c|c|c|c|c|c|}
\hline Rę & Variant & $N_{o b s}$ & $S I$ & Bias & Cor $_{E}$ & RMSE & Cor $_{S W H}$ & $a$ & $b$ \\
\hline \multirow{3}{*}{ Sevastopol } & V1 & 5996 & 0.363 & -0.255 & -0.443 & 0.384 & 0.900 & 0.807 & -0.050 \\
\hline & $\mathrm{V} 2$ & 6004 & 0.327 & 0.044 & 0.073 & 0.347 & 0.894 & 1.038 & 0.003 \\
\hline & V3 & 5991 & 0.292 & 0.072 & -0.033 & 0.308 & 0.907 & 0.985 & 0.087 \\
\hline \multirow{3}{*}{ Black Sea } & $\mathrm{V} 1$ & 138782 & 0.399 & -0.253 & -0.534 & 0.396 & & 0.758 & -0.012 \\
\hline & $\mathrm{V} 2$ & 138819 & 0.338 & 0.027 & -0.067 & 0.336 & 0.890 & 0.966 & 0.060 \\
\hline & V3 & 138758 & 0.320 & 0.066 & -0.134 & 0.317 & 0.898 & 0.938 & 0.127 \\
\hline
\end{tabular}

$\mathrm{N}$ o t e : $N_{o b s}$ is the number of altimetry measurements of the significant wave heights; SI is the scattering index between the forecasted and measured significant wave heights; Bias is the systematic deviation between the forecasted and measured heights of significant waves $S W H$; Cor $_{E}$ is the correlation coefficient between the deviations and the measured values $S W H$; RMSE is the standard deviation; CorswH is the correlation coefficient between the forecasted and measured SWH; $a$ and $b$ are the slope and displacement coefficients of the regression line, respectively. 

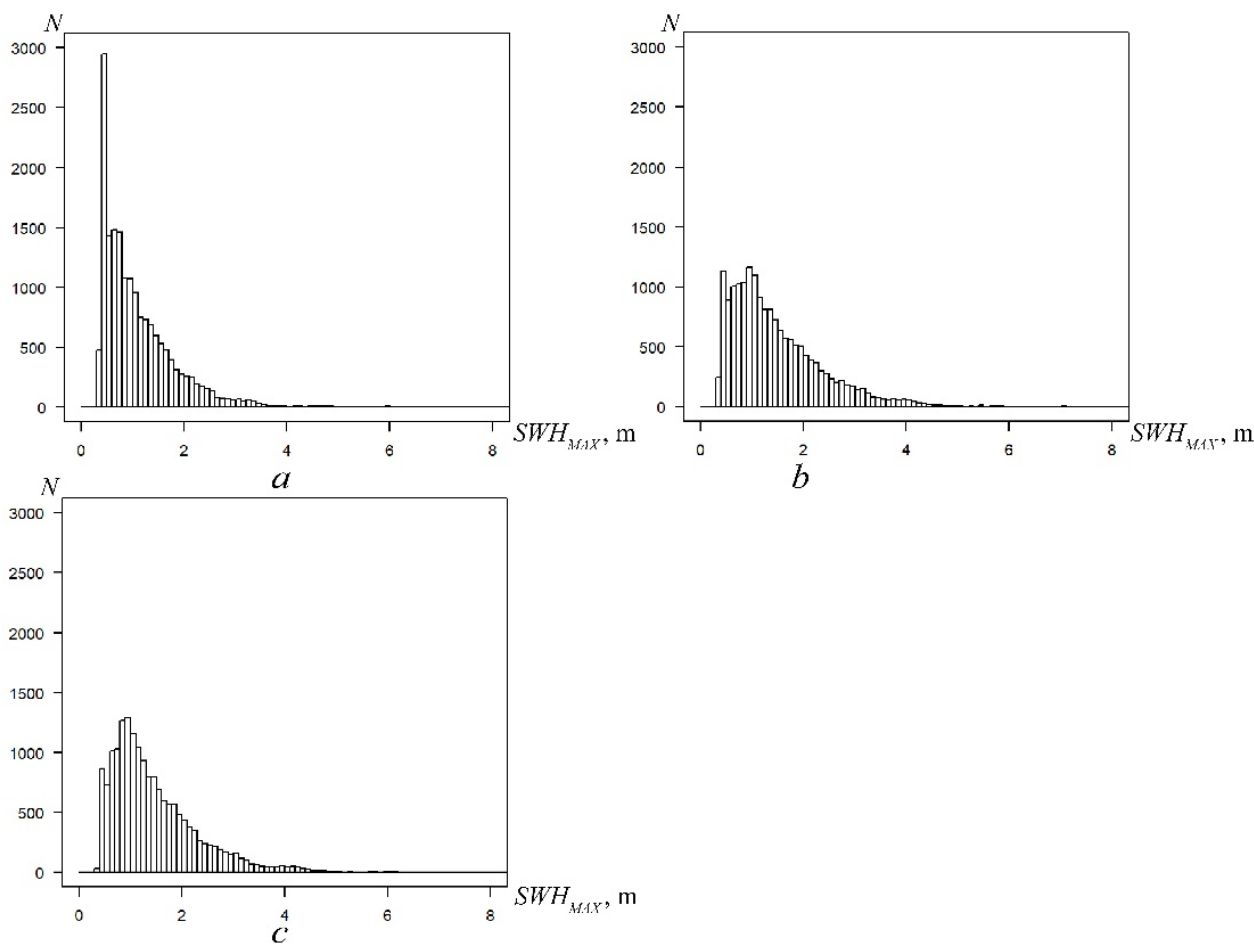

F i g. 5. Histograms of the wave maximum heights in the Sevastopol water area, 01.07.2017 01.07.2019: $a$ - variant V1; $b$ - variant V2; $c$ - variant V3

Fig. 5 shows the histograms of the distribution of the hourly maximum values of significant waves in the Sevastopol region, obtained from the results of calculations for three variants for $C_{d}(V)$ specifying for July 2017 - June 2019. The results presented in Fig. 5, demonstrate a significant underestimation of the heights of significant waves calculated using the model with the standard dependence $C_{d}(V)$ (variant V1). At the same time, in our opinion for variants V2 and V3, the distribution of the maximum heights of significant waves is more realistic.

Reliability of the diagnosis and prognosis results can be improved by making changes to the SWAN model software code. The introduction of these changes will provide the ability to set various functional $C_{d}(V)$ dependencies and involve measurement data of other characteristics of sea waves.

\section{Conclusions}

The modernized system provides a forecast of wind waves in the Sevastopol region with a high spatial resolution. It can be easily adapted to make forecasts in other coastal areas of the Black Sea. The proven procedure for the SWAN model tuning, based on changing the parameterization of the surface friction coefficient $C_{d}(V)$, permits to reduce the deviations of the heights of significant waves obtained PHYSICAL OCEANOGRAPHY VOL. 28 ISS. 5 (2021) 
based on predictive calculations from the values measured using satellite altimeters. The scattering index between the calculated and measured wave heights when adjusting the shape and coefficients of the $C_{d}(V)$ dependence can be reduced by $20 \%$ compared to the original parameterization used in SWAN model. The proposed model tuning procedure depends on the used wind speed data source, so in case of changes, it should be carried out again. The obtained results of the model tuning can be further refined and improved.

\section{REFERENCES}

1. The WAMDI group, 1988. The WAM Model - A Third Generation Ocean Wave Prediction Model. Journal of Physical Oceanography, 18(12), pp. 1775-1810. https://doi.org/10.1175/1520-0485(1988)018<1775:TWMTGO>2.0.CO;2

2. Tolman, H.L., 1991. A Third-Generation Model for Wind Waves on Slowly Varying, Unsteady, and Inhomogeneous Depths and Currents. Journal of Physical Oceanography, 21(6), pp. 782-797. https://doi.org/10.1175/15200485(1991)021<0782:ATGMFW>2.0.CO;2

3. The SWAN team, 2016. SWAN Cycle III version 42.10: Scientific and Technical Documentation. Delft, Netherlands: Delft University of Technology, 132 p.

4. Valchev, N.N., Trifonova, E.V. and Andreeva, N.K., 2012. Past and Recent Trends in the Western Black Sea Storminess. Natural Hazards and Earth System Sciences, 12(4), pp. 961-977. https://doi.org/10.5194/nhess-12-961-2012

5. Alekseev, D.V., Fomin, V.V., Ivancha, E.V., Kharitonova, L.V. and Cherkesov, L.V., 2012. Mathematical Simulation of Wind Waves in the Sevastopol Bay. Morskoy Gidrofizicheskiy Zhurnal, (1), pp. 75-84 (in Russian).

6. Arkhipkin, V.S., Gippius, F.N., Koltermann, K.P. and Surkova, G.V., 2014. Wind Waves in the Black Sea: Results of a Hindcast Study. Natural Hazards and Earth System Sciences, 14, pp. 2883-2897. https://doi.org/10.5194/nhess-14-2883-2014

7. Rusu, L., Bernardino, M. and Guedes Soares, C., 2014. Wind and Wave Modelling in the Black Sea. Journal of Operational Oceanography, 7(1), pp. 5-20. https://doi.org/10.1080/1755876X.2014.11020149

8. Van Vledder, G.Ph. and Akpınar, A., 2015. Wave Model Predictions in the Black Sea: Sensitivity to Wind Fields. Applied Ocean Research, 53, pp. 161-178. https://doi.org/10.1016/j.apor.2015.08.006

9. Myslenkov, S.A., Shestakova, A.A. and Toropov, P.A., 2016. Numerical Simulation of Storm Waves near the Northeastern Coast of the Black Sea. Russian Meteorology and Hydrology, 41(10), pp. 706-713. doi:10.3103/S106837391610006X

10. Divinsky, B.V. and Kosyan, R.D., 2018. Wave Climate of the Coastal Zone of the Crimean Peninsula. Physical Oceanography, 25(2), pp. 93-101. doi:10.22449/1573160X-2018-2-93-101

11. Ratner, Yu.B., Fomin, V.V., Ivanchik, A.M. and Ivanchik, M.V., 2017. System of the Wind Wave Operational Forecast by the Black Sea Marine Forecast Center. Physical Oceanography, (5), pp. 51-59. doi:10.22449/1573-160X-2017-5-51-59 
12. Korotaev, G.K., Ratner, Yu.B., Ivanchik, M.V., Kholod, A.L. and Ivanchik, A.M., 2016. Operational System for Diagnosis and Forecast of Hydrophysical Characteristics of the Black Sea. Izvestiya, Atmospheric and Oceanic Physics, 52(5), pp. 542-549. https://doi.org/10.1134/S0001433816050078

13. Grant, W.D. and Madsen, O.S., 1979. Combined Wave and Current Interaction with a Rough Bottom. Journal of Geophysical Research: Oceans, 84(C4), pp. 1797-1808. https://doi.org/10.1029/JC084iC04p01797

14. Papadopoulos, A., Katsafados, P., Kallos, G. and Nickovic, S., 2002. The Weather Forecasting System for Poseidon - An Overview. Journal of Atmospheric \& Ocean Science, 8(2-3), pp. 219-237. https://doi.org/10.1080/1023673029000003543

15. Ivanchik, A.M., 2014. [Management of the Functioning of Automated Systems of Marine Forecast]. In: Institute for Strategic Studies, 2014. Modern Problems of the Humanities and Natural Sciences: Materials of the XX International Scientific and Practical Conference. Moscow: Institute for Strategic Studies, pp. 56-61 (in Russian).

16. Myslenkov, S. and Chernyshova, A., 2016. Comparing Wave Heights Simulated in the Black Sea by the SWAN Model with Satellite Data and Direct Wave Measurements. Russian Journal of Earth Sciences, 16, ES5002. doi:10.2205/2016es000579

17. Akpinar, A. and Ponce de León, S., 2016. An Assessment of the Wind Re-Analyses in the Modelling of an Extreme Sea State in the Black Sea. Dynamics of Atmospheres and Oceans, 73, pp. 61-75. https://doi.org/10.1016/j.dynatmoce.2015.12.002

18. Wróbel-Niedźwiecka, I., Drozdowska, V. and Piskozub, J., 2019. Effect of Drag Coefficient Formula Choice on Wind Stress Climatology in the North Atlantic and the European Arctic. Oceanologia, 61(3), pp. 291-299. doi:10.1016/j.oceano.2019.02.002

19. Sterl, A., 2017. Drag at High Wind Velocities - a Review : Final Version. Technical report TR-361. De Bilt: KNMI, 33 p. Available at: http://publicaties.minienm.nl/documenten/drag-at-high-wind-velocities-a-review [Accessed: 16 August 2021].

20. Huang, C.H., 2012. Modification of the Charnock Wind Stress Formula to Include the Effects of Free Convection and Swell. In: Steven Jones (Ed.), 2012. Advanced Methods for Practical Applications in Fluid Mechanics. Rijeka: InTech, pp. 47-70. doi:10.5772/27003

21. Andreas, E.L., Mahrt, L. and Vickers, D., 2012. A New Drag Relation for Aerodynamically Rough Flow over the Ocean. Journal of the Atmospheric Sciences, 69(8), pp. 2520-2537. https://doi.org/10.1175/JAS-D-11-0312.1

22. Edson, J.B., Jampana, V., Weller, R.A., Bigorre, S.P., Plueddemann, A.J., Fairall, C.W., Miller, S.D., Mahrt, L., Vickers, D. and Hersbach, H., 2013. On the Exchange of Momentum over the Open Ocean. Journal of Physical Oceanography, 43(8), pp. 1589-1610. https://doi.org/10.1175/JPO-D-12-0173.1

23. Large, W.G. and Yeager, S., 2004. Diurnal to Decadal Global Forcing for Ocean and Sea-ice Models: The Data Sets and Flux Climatologies. Boulder, USA: National Center for Atmospheric Research, 112 p. doi:10.5065/D6KK98Q6 
24. Cavaleri, L., Abdalla, S., Benetazzo, A., Bertotti, L., Bidlot, J.-R., Breivik, Ø., Carniel, S., Jensen, R.E. and Portilla-Yandun, J., 2018. Wave Modelling in Coastal and Inner Seas. Progress in Oceanography, 167, pp. 164-233. https://doi.org/10.1016/j.pocean.2018.03.010

25. Repina, I.A., Artamonov, A.Yu., Varentsov, M.I. and Kozyrev, A.V., 2015. Experimental Study of High Wind Sea Surface Drag Coefficient. Physical Oceanography, (1), pp. 49-58. doi:10.22449/1573-160X-2015-1-49-58

26. Zelenko, A.A., Strukov, B.S., Resnyansky, Yu.D. and Martynov, S.L., 2014. S.L. A System of Wind Wave Forecasting in the World Ocean and Seas of Russia. In: SOI`s Proceedings. Moscow: SOI. Vol. 215: Research of Oceans and Seas, pp. 90101 (in Russian).

27. Dimitrova, M., Kortcheva, A. and Galabov, V., 2013. Validation of the Operational Wave Model WAVEWATCH III against Altimetry Data from JASON-2 Satellite. Bulgarian Journal of Meteorology and Hydrology, 18(1-2), pp. 4-17.

28. Strukov, B.S., Zelenko, A.A., Resnyansky, Yu.D. and Martynov, S.L., 2013. [The System for Predicting the Characteristics of Wind Waves and the Results of Its Tests for the Waters of the Azov, Black and Caspian Seas]. In: A.A. Alekseeva, ed., 2013. [Information Collection No. 40. New Technologies, Models and Methods of the Hydrometeorological Forecasts and the Results of Their Operational Tests]. Moscow, Obninsk: IG-SOCIN, pp. 6479. Available at: http://method.meteorf.ru/publ/sb/sb40/sb40.pdf [Accessed: 20 September 2021] (in Russian).

29. Stoliarova, E.V. and Myslenkov, S.A., 2015. High Resolution Wave Forecast System in Kerch Strait. In: E. S. Nesterov, ed., 2015. Proceedings of Hydrometcentre of Russia. Moscow: TRIADA LTD, 2015. Issue 354, pp. 24-35. Available at: http://method.meteorf.ru/publ/tr/tr354/tr354.pdf [Accessed: 13 August 2021] (in Russian).

30. Akpınar, A., van Vledder, G.Ph., Kömürcü, M.İ. and Özger, M., 2012. Evaluation of the Numerical Wave Model (SWAN) for Wave Simulation in the Black Sea. Continental Shelf Research, 50-51, pp. 80-99. https://doi.org/10.1016/j.csr.2012.09.012

31. Kutupoğlu, V., Çakmak, R.E., Akpınar, A. and van Vledder, G.Ph., 2018. Setup and Evaluation of a SWAN Wind Wave Model for the Sea of Marmara. Ocean Engineering, 165, pp. 450-464. https://doi.org/10.1016/j.oceaneng.2018.07.053

32. Rusu, E., 2009. Wave Energy Assessments in the Black Sea. Journal of Marine Science and Technology, 14(3), pp. 59-372. https://doi.org/10.1007/s00773-0090053-6

About the authors:

Yuri B. Ratner, Head of the Laboratory of Marine Forecasts, Marine Hydrophysical Institute of RAS (2 Kapitanskaya St., Sevastopol, 299011, Russian Federation), Ph. D., ORCID ID: 0000-0002-9250-7743, ResearcherID: AAY-1101-2021, yubrat@gmail.com 
Vladimir V. Fomin, Head of the Department of Computer Science and Mathematical Modeling, Marine Hydrophysical Institute of RAS (2 Kapitanskaya St., Sevastopol, 299011, Russian Federation), Dr. Sci., ORCID ID: 0000-0002-9070-4460, v.fomin@ukr.net

Anton L. Kholod, Marine Hydrophysical Institute of RAS (2 Kapitanskaya St., Sevastopol, 299011, Russian Federation), Ph. D., ORCID ID: 0000-0003-4694-8406, ResearcherID: ABA3482-2020, antonholod@mail.ru

Antonina M. Ivanchik, Leading Software Engineer of the Laboratory of Marine Forecasts, Marine Hydrophysical Institute of RAS (2 Kapitanskaya St., Sevastopol, Russian Federation, 299011), ORCID ID: 0000-0003-4354-7965, antonishka@gmail.com

Contribution of the co-authors:

Yuri B. Ratner - necessity of correcting the wind friction coefficient to take into account the regional features of the interaction of the sea surface and the lower atmosphere in the Sevastopol region is substantiated; a procedure for friction coefficient correction the without changing the SWAN model code is proposed; analysis of the validation results of the calculated heights of significant waves in the Sevastopol region and the entire Black Sea area

Vladimir V. Fomin - adaptation of the SWAN model to carry out calculations of the heights of significant waves and other characteristics of sea waves in the Sevastopol region with high spatial resolution; analysis of the validation results of the calculated heights of significant waves in the Sevastopol region and the entire Black Sea area

Anton L. Kholod - validation of the results of calculations of the significant wave heights in the Sevastopol region and the Black Sea

Antonina M. Ivanchik - modernization of the automatic system for the diagnosis and forecast of sea waves for calculations in the Sevastopol region with high spatial resolution and the implementation of methods for correcting the wind friction coefficient; sea waves calculations using an upgraded automatic system

All the authors have read and approved the final manuscript.

The authors declare that they have no conflict of interest. 